\title{
Psychosocial predictors of health-related quality of life and health service utilisation in people with chronic low back pain
}

\author{
Philip Keeley ${ }^{\mathrm{a}, *}$, Francis Creed ${ }^{\mathrm{b}}$, Barbara Tomenson ${ }^{\mathrm{b}}$, \\ Chris Todd ${ }^{a}$, Gunilla Borglin ${ }^{\mathrm{a}}$, Chris Dickens ${ }^{\mathrm{b}}$ \\ a Department of Nursing, Midwifery \& Social Work, Coupland III Building, University of Manchester, Oxford Road, Manchester M13 9PL, UK \\ ${ }^{\mathrm{b}}$ Department of Psychiatry, University of Manchester, UK
}

Received 10 November 2006; received in revised form 17 May 2007; accepted 17 May 2007

\begin{abstract}
Psychological and social factors have been shown, separately, to predict outcome in individuals with chronic low back pain. Few previous studies, however, have integrated both psychological and social factors, using prospective study of clinic populations of low back pain patients, to identify which are the most important targets for treatment. One hundred and eight patients with chronic low back pain, newly referred to an orthopaedic outpatient clinic, completed assessments of demographic characteristics, details of back pain, measures of anxiety and depression (Hospital Anxiety and Depression Scale, HADS), fearful beliefs about pain (Fear Avoidance Beliefs Questionnaire), social stresses (Life Events and Difficulties Schedule) and physical aspects of health-related quality of life [SF-36 Physical Component summary Score scale (PCS)]. Six months later subjects completed the SF-36 PCS and the number of healthcare contacts during follow-up was recorded. Independent predictors of SF-36 PCS at 6-month follow-up were duration of pain [(standardised regression coefficient $(\beta)=-0.18, p=0.04)$, HADS score $(\beta)=-0.27, p=0.003$ ] and back pain related social difficulties $(\beta=-0.42, p<0.0005)$. Number of healthcare contacts over the 6 months ranged from 1 to 29 , and was independently predicted by perceived cause of pain [Incident Rate Ratio (IRR) $=1.46, p=0.03$ ], Fear Avoidance Beliefs about work (IRR $=1.02$, $p=0.009$ ) and back pain related social difficulties (IRR $=1.16, p=0.03$ ). To conclude, anxiety, depression, fear avoidance beliefs relating to work and back pain related stresses predict impairment in subsequent physical health-related quality of life and number of healthcare contacts. Interventions targeting these psychosocial variables in clinic patients may lead to improved quality of life and healthcare costs.
\end{abstract}

(C) 2007 International Association for the Study of Pain. Published by Elsevier B.V. All rights reserved.

Keywords: Low back pain; Prospective study; Depression; Anxiety; Fear-avoidance beliefs; Social adversity; Quality of life

\section{Introduction}

The role of psychological factors in determining outcomes in individuals with back pain has been the subject of considerable recent research. Depression and fearavoidance predict disability, time off work, and healthcare utilisation (Sullivan et al., 2003, 2005a, 2006a;

\footnotetext{
* Corresponding author. Tel.: +44 0161275 5578; fax: +44 0161275 5542.

E-mail address: philip.keeley@manchester.ac.uk (P. Keeley).
}

Smith et al., 2004; Boersma and Linton, 2005b; Carragee et al., 2005), though their predictive power may depend on the chronicity of the pain (Boersma and Linton, 2005a, 2006). Use of maladaptive coping strategies, such as distraction and praying, predicts poorer functional adjustment, and adopting a helpless/hopeless position predicts worse emotional outcomes (Koleck et al., 2006). Perceived support and stress in the work place may predict delayed return to work, though the evidence is mixed (Pincus et al., 2002; Hartvigsen et al., 2004). Intervention studies provide the strongest evidence of causal association and have demonstrated 
that improvements in depression and pain-related cognitions, particularly improvements in pain catastrophisation, are associated with return to work in individuals with chronic musculoskeletal pain (Sullivan et al., 2005b, 2006a,b).

Social factors are also important predictors of outcome in back pain. Education, socio-economic status and unemployment predict back pain duration and recurrence, though it is not clear from existing literature how these exert their effect on outcome (Dionne et al., 2001). Such social characteristics are likely to be closely associated with psychological variables, acting as both precipitating and maintaining factors for psychological problems. Whilst previous research has investigated psychological and social factors separately, no previous study has investigated the relative importance of both social and psychological factors, measured together, in determining outcomes in clinical populations with chronic low back pain. Until the relative importance of these factors is precisely understood, treatment strategies may be less than optimal (Pincus et al., 2002).

We have performed a prospective cohort study in a consecutive series of patients with simple, mechanical low back pain (LBP), newly referred to an orthopaedic clinic in an inner city hospital in the UK. We aimed to determine the relative importance of both social and psychological factors at baseline in predicting outcomes 6 months later. We investigated two main outcomes, the physical aspects of health-related quality of life (physical HRQoL) and health service utilisation, as these are important outcomes of back pain. We tested the hypothesis that emotional factors (anxiety and depression), cognitive factors (beliefs relating to pain) and social stresses would independently predict physical HRQoL and health service utilisation over the 6 months of follow-up, after controlling for the effects of socio-demographic characteristics. Our study is exceptional due to the rigour with which we have assessed social factors, recording stresses that are both related to and independent of back pain, to clarify the nature of the causal link between social stresses and outcomes.

\section{Methods}

Consecutive subjects with low back pain of 6 months or longer were recruited at their first appointment at an orthopaedic outpatient clinic following referral by their General Practitioner (GP). Inclusion criteria were: primary complaint of simple, mechanical LBP, aged 18-65 years with English language skills sufficient to allow completion of questionnaires. Subjects were excluded if they suffered from any other medical condition that was judged likely to have a major impact on their physical HRQoL or if their back pain was part of a systemic or malignant disease. After full explanation consent was obtained from each participant. Approval for the study was granted by the Central Manchester Local Research Ethics Committee.
All subjects completed questionnaires recording the following demographic information: age, sex, years of formal educational, marital status (living with partner versus other) and employment status. Socioeconomic status was based on current or past employment (or partners employment if never employed), categorised using the criteria of Goldthorpe and Hope and dichotomised into high or low socio-economic status based on whether the subjects were employed in non-manual or manual work, respectively, which we felt was particularly relevant to individuals disabled with chronic low back pain (Goldthorpe and Hope, 1974). The Goldthorpe and Hope classification has been used extensively in research (Rose and Pevalin 2001), which facilitates comparison with previous studies.

Details of back pain included the patient's view regarding the cause of the pain (trauma, "wear and tear" or unknown cause), the duration of low back pain (years) and whether the individual was currently seeking medico-legal compensation related to their back pain.

The Hospital Anxiety and Depression Scale (HADS) was used to measure symptoms of anxiety and depression (Zigmond and Snaith, 1983). The HADS was designed for use in people with physical illness as it omits the bodily symptoms of depression that may be caused by physical illness (such as loss of appetite and sleep disturbance). This self-rated questionnaire consists of 14 items ( 7 for anxiety and 7 for depression), each item is scored $0-3$, with high scores representing high levels of symptoms of anxiety and/or depression. A score 11 or above on either scale indicates probable anxiety or depressive disorder. In view of the high correlation between anxiety and depression scores a combined score (i.e. the total Hospital Anxiety and Depression Scale score) was used for the main analyses.

The Fear-Avoidance Beliefs Questionnaire (FABQ) was used to elicit individuals' beliefs about the extent to which physical activity and work affects low back pain. The questionnaire was developed and has been successfully used in mixed samples of working and unemployed people. (Waddell et al., 1993; Pfingsten et al., 2000; Swinkels-Meewisse et al., 2006). The questionnaire assesses the tendency to avoid activity and work as the result of the experience of pain. For these purposes work can be paid employment or activity within the home and candidates were briefed to complete the assessment on this basis. This questionnaire consists of 16 statements for which participants respond using a scale from 0 to 6 . The first section of the FABQ includes five questions relating to fear-avoidance beliefs about physical activity, with four of the questions used to calculate the FAB activity score. The second section includes 11 questions, with seven of the questions used to calculate the fear-avoidance beliefs about work (FAB work score). On both subscales high scores represent a greater tendency to avoid work/activity.

Social stress was measured using the Life Events and Difficulties Schedule (LEDS) (Brown and Harris, 1978), a semistandardised research interview. The trained interviewer (P.K.) asked in detail about the timing, nature and impact of discrete, stressful "life events" (e.g. bereavement) and ongoing stressful "chronic difficulties" (e.g. serious ongoing marital difficulties) over the year before recruitment. The rating of severity and independence of each life event was made by a panel of experienced LEDS interviewers, blind to the severity of back 
pain and the respondent's distress. The rating of severity was made according to a dictionary of standardised vignettes to maximise consistency with other projects. Life Events and Difficulties Schedule were recorded of the 12 months prior to the baseline interview and in this paper 2 measures are quoted: (a) whether subjects had experienced a severe stress or marked chronic difficulty in the year before assessment and (b) a summary score that takes into account the number and severity with high scores representing experience of more severe stresses.

The interview identified separately those stresses that were related to back pain (e.g. unemployment, financial difficulties) and from those that were independent of back pain (such as death of a close relative, aggravated theft of property), so that we could assess the effect of both of these on outcome.

\subsection{Outcome measures}

\subsubsection{Physical health-related quality of life}

We used the UK version of the 36-item Short-Form Health Survey (SF-36) Physical Component Score (PCS) as a measure of physical HRQoL, based on 4 dimensions of physical health status: physical function, physical role, body pain and general health (Ware and Sherbourne, 1992; Ware et al., 1994, 1995). We did not include the Mental Component Score (MCS) as an important outcome due to similarities in the items on the HADS scale and the MCS, which would inevitably increase the association between anxiety and depression on the one hand, and HRQoL on the other. The SF-36 PCS has advantages over its four constituent dimensions, being more sensitive to change, eliminating floor and ceiling effects and reducing the number of statistical comparisons performed (Ware et al., 1995, 1994). The SF-36 PCS, measured at the end of a period of rehabilitation, has been shown to be closely associated with subsequent return to work and socio-economic outcomes (Gatchel et al., 1999).

The Physical Component Score is standardised to the general population (mean score, 50; standard deviation 10), with high scores representing higher levels of functioning. Physical HRQoL was assessed both at base line and 6 months after recruitment.

\subsubsection{Health service utilisation}

Health service utilisation data for the 6 months following recruitment were collected using the Client Socio-Demographic and Service Receipt Inventory (CSSRI) (Beecham and Knapp, 1992). Patients completed this self-report assessment recording details of hospital outpatient, in-patient or day case attendance, any operations or surgical procedures, and contact with accident and emergency services. Details of any contacts with healthcare professionals in the primary care setting were recorded, including the number and duration of GP visits, interventions performed along with any urgent home visits. For the purposes of this study, total number of contacts with healthcare services was used as the outcome of interest. Health service utilisation data collected using this questionnaire have been shown to compare well with data collected from inspection of medical records (Little et al., 2001).

\subsection{Statistical analyses}

Descriptive data are presented as means (standard deviations) or as number of subjects (percentages). Comparisons across groups were performed using $t$-tests, ANOVAs, Chisquare tests or Fisher's Exact Test (FET) and bivariate associations were assessed using Pearson's or Spearman's correlation coefficients, as appropriate.

Multiple regression analyses were used to identify independent predictors of SF-36 PCS at 6 months follow-up. Baseline variables showing significant $(p<0.05)$ or near significant $(p<0.2)$ univariate associations with SF-36 PCS at 6 months follow-up were entered as independent variables. Independent variables were entered in sequential blocks to determine whether emotional state, cognitive factors and social stress made a significant additional contribution to the regression model, after demographic characteristics, duration and perceived cause of back pain had been entered. For the main analysis, independent variables were in the following order: (i) Block 1 - age, educational status, (ii) Block 2 - duration of back pain and perceived cause of back pain (categorised into unknown cause versus others), and (iii) Block 3 - total HADS score (combined anxiety and depression score), fear-avoidance beliefs (for work and activity separately) and presence of severe social stress in the past year (back pain related and back pain independent). This regression analysis was repeated including the SF-36 PCS at baseline in Block 1, with other variables added as above.

Assessments for problems of multi-colinearity due to associations between independent variable were performed for the multiple regression analyses. Due to a high degree of association between sociodemographic variables (socioeconomic, employment and educational status), the initial model including all three of these variables had problems with multicolinearity. After exclusion of socioeconomic and employment status, all Variance Inflation Factors (VIFs) fell within normal limits, (i.e. VIF $<2$ ), without altering which variables from Block 3 contributed to the model. For the sake of brevity we have presented only the regression models with socioeconomic and employment status excluded. It is noteworthy, however, that the contribution of HADS score and back pain related stresses continued to contribute significantly to the model if employment status or socioeconomic status were used instead of educational status.

Due to the fact that health service utilisation was recorded using total count of health service contacts, negative binomial regression was used to investigate predictors of number of health service contacts. The same independent variables in the same order were added as for SF-36 PCS. Results are presented as Incident Rate Ratios (IRRs) with $p$-values and confidence intervals.

\section{Results}

One hundred and twenty patients were eligible to participate in the study (Table 1). One hundred and eight people completed baseline assessments $(90 \%$ response rate). The main baseline characteristics of this sample can be seen in Table 1 . 
Table 1

Baseline characteristics of group

\begin{tabular}{ll}
\hline Investigated variables & $\begin{array}{l}N(\%) / \text { mean } \\
(\mathrm{SD})^{\mathrm{a}}\end{array}$ \\
\hline Age - mean (SD) & $39.9(12.2)$ years \\
Male & $60(55.6 \%)$ \\
Living with partner & $65(60.2 \%)$ \\
Other & $43(29.8 \%)$ \\
Close confidant & $96(88.9 \%)$ \\
High socio-economic group & $52(48.1 \%)$ \\
Low socio-economic group & $56(51.9 \%)$ \\
Education $\geqslant 12$ years education & $48(44.4 \%)$ \\
Employed & $62(57.4 \%)$ \\
Duration of back pain - mean (SD) & $5.5(5.7)$ years, \\
& median $=4.0$ \\
Cause of pain - none known & $62(57.4 \%)$ \\
Cause of pain - accident/trauma & $34(31.5 \%)$ \\
Cause of pain - chronic "heavy work" & $12(11.1 \%)$ \\
Claiming or claimed medico-legal & $15(13.9 \%)$ \\
$\quad$ compensation for back pain & \\
HAD depression score (mean, SD) & $7.4(4.4 \%)$ \\
HAD depression score $\geqslant 11$ & $27(25.0 \%)$ \\
HAD anxiety score mean (SD) & $9.0(4.1)$ \\
HAD anxiety score $\geqslant 11$ & $39(36.1 \%)$ \\
Fear avoidance Beliefs - work score - mean (SD) & $20.6(12.4)$ \\
Fear avoidance Beliefs - activity score - mean (SD) & $16.5(5.6)$ \\
Physical HRQoL score (SF-36) - mean (SD) & $33.3(10.1)$ \\
Mental HRQoL score (SF-36) - mean (SD) & $44.0(11.5)$ \\
Severe events in past year/marked difficulties (\%) & $46(49.5)$ \\
Median social stress summary score (IQR) & \\
Back pain related social stresses & $1.0(0.0-3.0)$ \\
Back pain independent social stresses & $1.0(0.0-3.5)$ \\
\hline
\end{tabular}

${ }^{a}$ Results given represent the number of subjects (with percentages) unless otherwise stated IQR, interquartile range.

High degrees of association were evident between educational status, employment and socioeconomic status. Compared to subjects with at least 12 years of education, subjects with less than 12 years of education were more likely to unemployed [8 $(19 \%)$ versus $21(56.9 \%)$, respectively, Fisher's Exact Test $p<0.0005]$ and more likely to be of lower socio-economic status [7 (16.7\%) versus $41(80.4 \%)$, respectively, Fisher's Exact Test $p<0.0005]$. For the purposes of the multiple regression analyses only education was entered in block 1 , to avoid problems with multicolinearity.

HAD anxiety and depression sub-scores were significantly correlated with each other (Pearson's $r=0.59$, $p<0.0005$ ), so for the purposes of the main analyses HADS total score (i.e. combined anxiety and depression scores) was used. HADS total scores were highest in subjects with low educational status $(t=4.01$, $p<0.0005)$ and those who were unemployed $(t=5.3$, $p<0.0005)$. The same was true of FAB scores; FAB scores relating to activity $(t=3.6, p<0.0005)$ and work $(t=4.6, p<0.0005)$ were greatest in those of low educational status, and the unemployed $(t=3.7, p<0.0005$ and $t=5.3, p<0.0005$, respectively). FAB relating to activity and work were significantly associated with HADS total score (Pearson's $r=0.37, p<0.0005$ and $r=0.43, p<0.0005$, respectively).

\subsection{Follow-up at 6 months}

\subsubsection{Physical health-related quality of life}

Ninety-three people ( $86 \%$ of 108 eligible subjects) completed the SF-36 questionnaire at 6 months followup. There were no differences between those who were followed up and those who dropped out with regard to socio-demographic variables, nature of back pain, emotional or cognitive characteristics, or SF-36 PCS. At follow-up the mean SF-36 PCS was 34.9 (SD 10.9) compared to the baseline score of 33.3 (SD 10.1) in the same subjects $(n=93)$. Of the 37 subjects unemployed at baseline, only $2(5 \%)$ returned to work during our follow-up. Baseline variables significantly and near significantly associated with SF-36 PCS at 6 months are shown in Table 2.

\subsubsection{Baseline predictors of SF-36 Physical Component Score at 6 months follow-up}

The results of the multiple regression analysis to investigate baseline predictors of physical HRQoL at 6 months are presented in Table 3. The model predicted a total of $50 \%$ (adjusted $R^{2}$ ) of the variance of the SF36 Physical Component Score at follow-up. In the final model the baseline factors that made a significant independent contribution to SF-36 Physical Component Score 6 months later were duration of back pain, HADS total score and back pain related social stresses.

When the multiple regression analysis was repeated with baseline physical HRQoL score added in Block 1, the variance of the SF-36 Physical Component Score at follow-up that was accounted for by the model increased to $72 \%$ (Table 4). In this revised model baseline SF-36 PCS contributed significantly to the model. Despite this, HADS total score and back pain related social stresses, entered in Block 3, continued to contribute significantly to the model.

\subsubsection{Health service utilisation}

Eighty-six people ( $80 \%$ of 108 eligible subjects) completed the CSSRI assessment at 6-month follow-up. The median number of health service contacts was 4 (interquartile range 2.0-8.0), with a range of 1-29 contacts in the 6 months following recruitment. Seventeen patients $(20 \%)$ had 10 or more healthcare contacts over the 6 months follow-up period.

\subsubsection{Baseline predictors of health service contact during 6-month follow-up}

Health service contacts during the 6 months of the study were independently predicted by cause of back pain (pain attributed to traumatic cause associated with greater impairment in physical HRQoL), more fearful cognitions relating to work and back pain related social stresses. HADS total score and Fear avoidance beliefs about activity were not independent predictors. When 
Table 2

Univariate associations with physical HRQoL score at 6 months follow-up

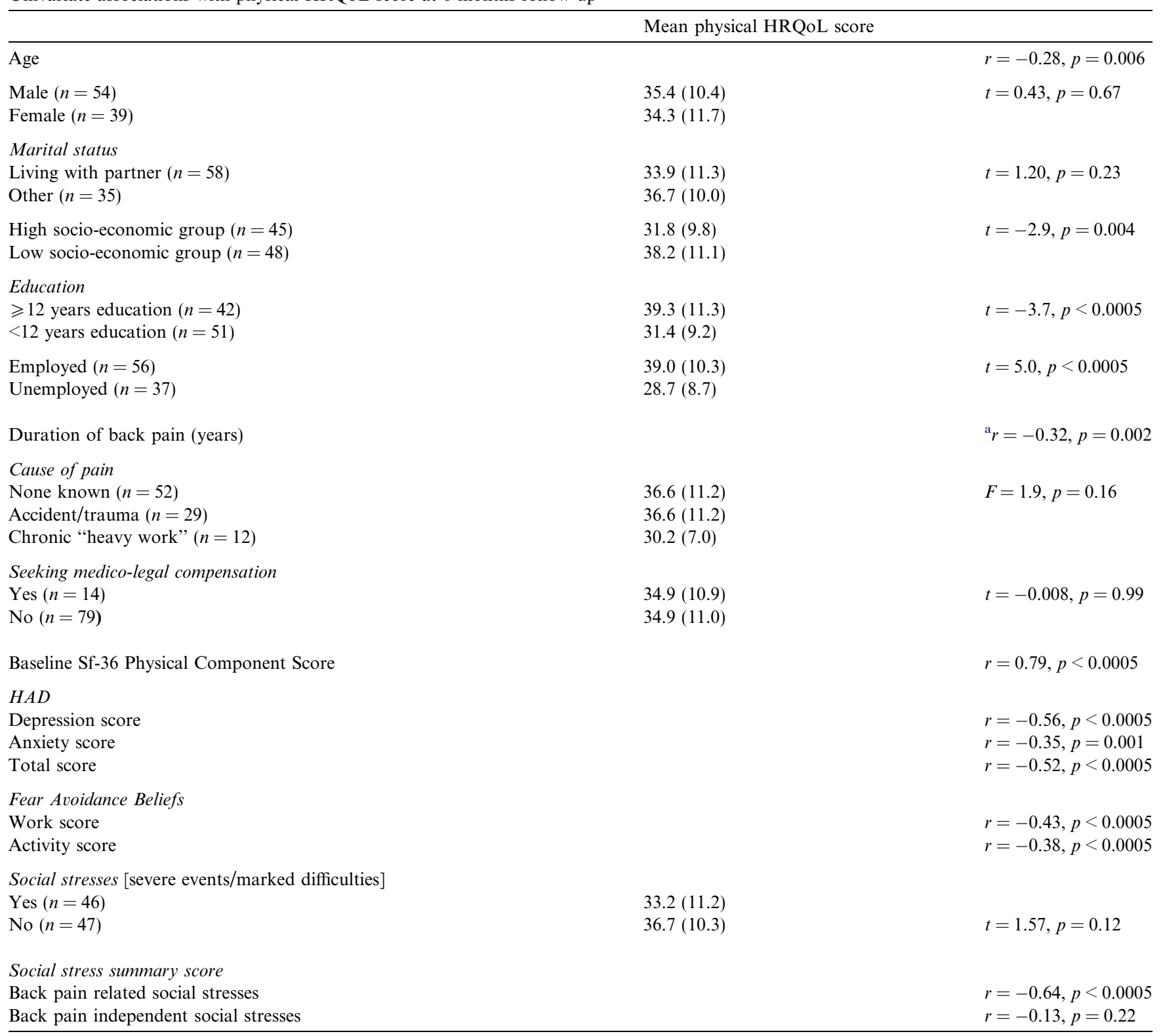

${ }^{\text {a }} r$, Spearman's correlation coefficient; PCS, SF-36 Physical Component Score.

this negative binomial regression was repeated including SF-36 PCS at baseline in block 1, Fear avoidance beliefs relating to work continued to contribute to the model (IRR $=1.02, p=0.008,95 \%$ confidence intervals $1.01-$ 1.03) but back pain related stresses did not $(\mathrm{IRR}=1.12, p=0.09)($ Table 5$)$.

\section{Discussion}

In this prospective cohort study of chronic low back pain sufferers our most notable findings were that social stresses predicted subsequent impairment in physical HRQoL and number of healthcare contacts over the 6-month follow-up period. This effect was limited to social stresses related to the back pain (e.g. unemployment due to back pain); social stresses independent of the back pain (e.g. death of a close relative) did not have any effect on subsequent physical HRQoL or healthcare contacts. The contribution of work related social stresses was independent of demographic characteristics, cause and duration of back pain and the contribution of other psychological variables. In addition to the effects of social stresses, depression score at first clinic visit also predicted self-rated physical HRQoL 6 months later and Fear Avoidance Beliefs relating to work predicted number of health service contacts during follow-up. Thus our hypothesis was upheld. 
Table 3

Multiple regression analysis to identify baseline variables that contribute physical HRQoL score 6 months later

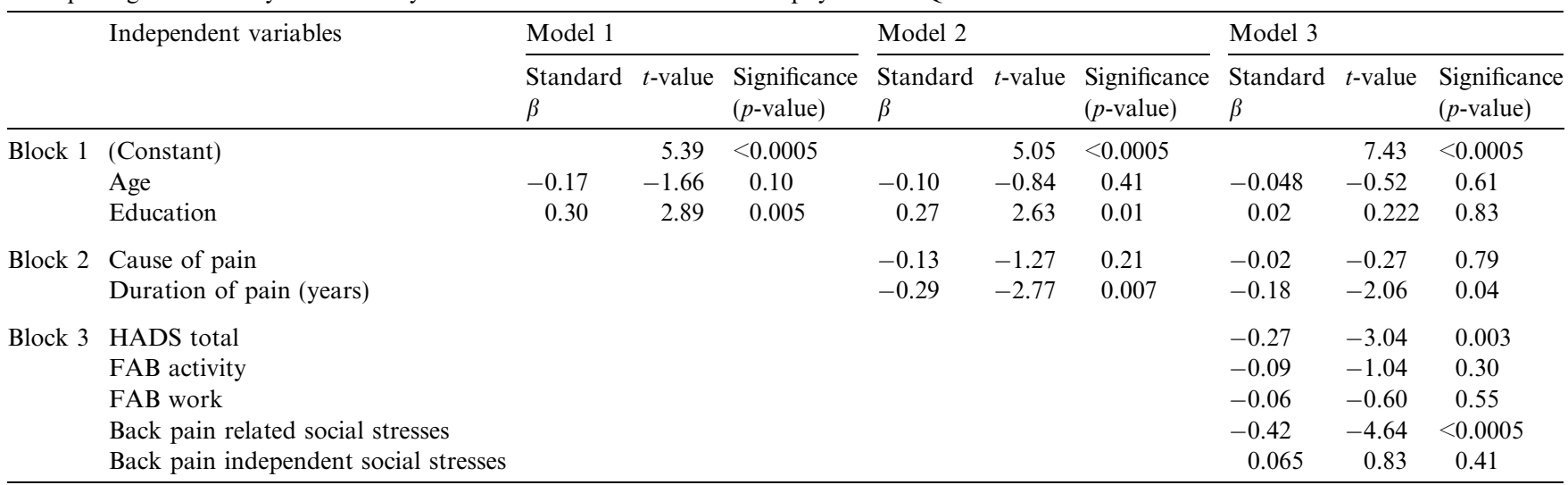

Model 1: $R^{2}=0.16$, adjusted $R^{2}=0.14, R^{2}$ change $=0.16, F$ change $=8.4$, significance of $F$ change $p<0.0005$.

Model 2: $R^{2}=0.24$, adjusted $R^{2}=0.20, R^{2}$ change $=0.08, F$ change $=4.6$, significance of $F$ change $p=0.012$.

Model 3: $R^{2}=0.55$, adjusted $R^{2}=0.50, R^{2}$ change $=0.31, F$ change $=11.2$, significance of $F$ change $p<0.0005$

There were no problems with multicolinearity of independent variables. All variance inflation factors $<2.0$.

Our sample was representative of those attending a hospital orthopaedic clinic with a primary complaint of low back pain, so we believe our results are likely to be generalisable to the many patients seeking help for back pain in secondary care. Other strengths of our study were the simultaneous measurement of several key variables at baseline using well-validated and specific assessments. Our measure of socio-economic status, based solely on occupation, might be considered old fashioned, since many more recent measures take into account factors such as employment relations and conditions of employment. We considered, however, the division of subjects into those involved in manual labour or not, to be most relevant to a population with chronic low back pain.
This is the first prospective study in a clinical population to examine the importance of social stresses in such detail. Demographic variables and duration of back pain accounted for the majority of variance in physical HRQoL and healthcare costs, by virtue of the fact they were forced into the regression equation first. After demographic variables and duration of back pain had been entered into the analysis, social stresses and HADS total score continued to predict a significant proportion of the variance of SF-36 PCS at follow-up. This reflects the fact that the observed contribution to the model of these variables was independent of the confounding or mediating influence of the demographic and back pain variables.

Table 4

Multiple regression analysis to identify baseline variables that contribute physical HRQoL 6 months later: including baseline physical HRQoL as independent variable

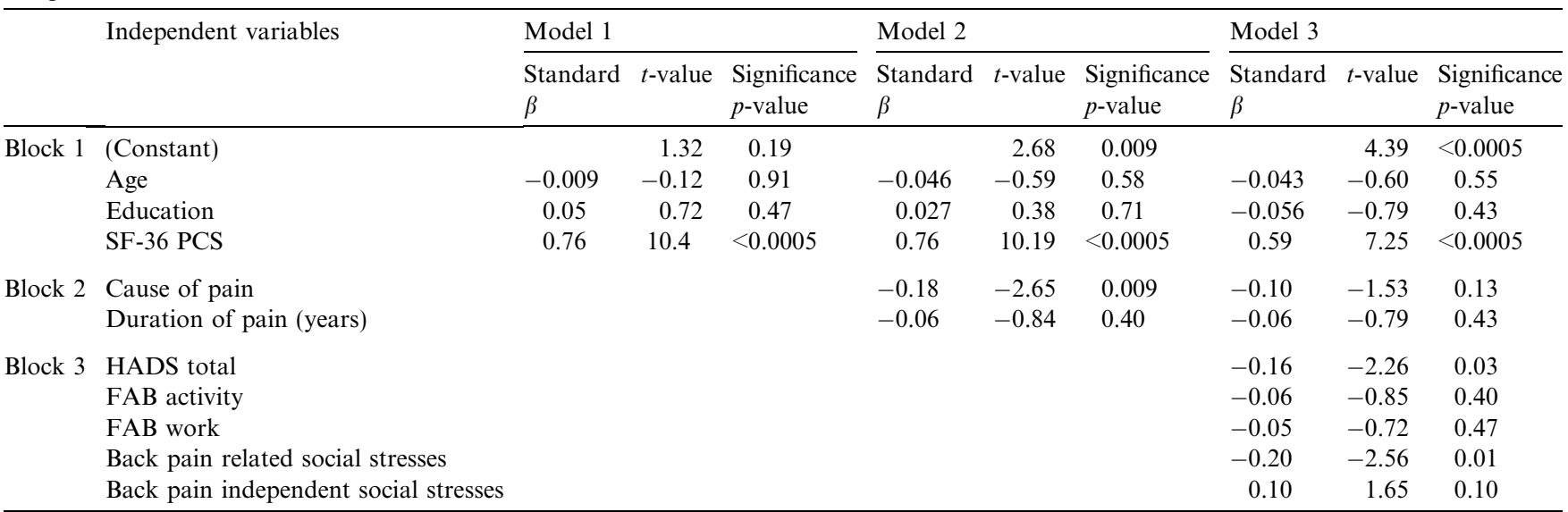

Model 1: $R^{2}=0.62$, adjusted $R^{2}=0.61, R^{2}$ change $=0.62, F$ change $=48.6$, significance of $F$ change $p<0.0005$

Model 2: $R^{2}=0.65$, adjusted $R^{2}=0.63, R^{2}$ change $=0.03, F$ change $=3.9$, significance of $F$ change $p=0.02$.

Model 3: $R^{2}=0.72$, adjusted $R^{2}=0.69, R^{2}$ change $=0.07, F$ change $=4.20$, significance of $F$ change $p=0.002$.

There were no problems with multicolinearity of independent variables. All variance inflation factors $<2.0$. 


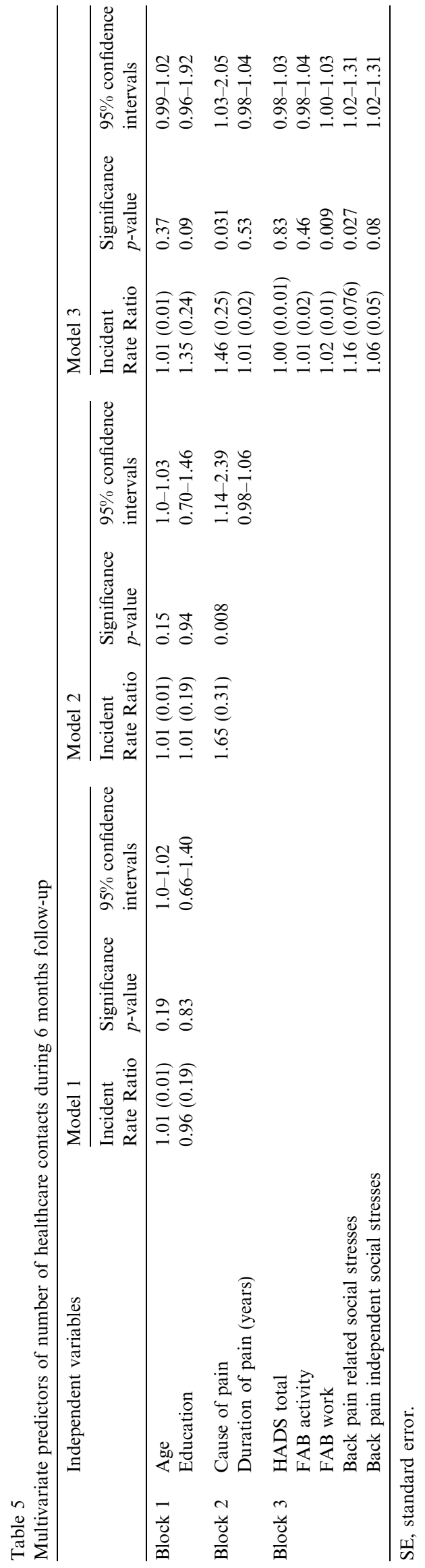

Our rigorous measure of social stresses enabled us to determine whether stresses were related to or independent of back pain. Since the adverse effects of social stresses on subsequent physical HRQoL and healthcare contacts were limited to those stresses that were associated with the back pain, it is possible that the observed association between stresses and physical HRQoL could be attributed to the severity of back pain. Against this suggestion, however, in the analysis concerning predictors of subsequent SF-36 PCS, is our finding that back pain related stresses continued to be independent predictors after baseline SF-36 PCS had been added in block 1 . Since baseline SF-36 PCS contains assessments of pain and disability, our findings indicate that some of the effect of back pain related stresses on subsequent physical HRQoL was independent of the confounding effect of severe, disabling back pain.

Our finding that Fear Avoidance Beliefs in chronic low back pain sufferers predict health care utilisation has not been reported previously. Whilst Fear Avoidance Beliefs have been shown to predict level of pain and disability among back pain sufferers (Al Obaidi et al., 2000; Linton, 2000; Vlaeyen and Linton, 2000), which might lead to individuals seeking more health care, among our patients the contribution of Fear Avoidance Beliefs persisted after the effects of SF-36 Physical Component Score at baseline had been controlled. The latter contained assessments of pain and disability, suggesting that the impact of fearful beliefs relating to work on health care contacts was independent of levels of pain and disability. Other research has linked Fear Avoidance Beliefs to poor coping among chronic low back pain patients; anxious cognitions were associated with a diminished sense of control, and avoidance to an increase in pain behaviours (Asmundson et al., 1999). It is possible that Fear Avoidance Beliefs among our chronically disabled pain patients led to increased health care utilisation as part of a maladaptive coping response to chronic pain. The contribution of back pain related stresses to healthcare utilisation became non-significant after controlling for Baseline SF-36 PCS. Using the same arguments as above this indicates a possible confounding influence of severity of back pain.

The clinical implications of our findings are that clinician should remain aware that social stresses are important predictors of physical HRQoL and healthcare utilisation, and that they should evaluate such factors as part of routine assessment. Though the observed effects may be limited to stresses that result directly from the back pain itself, this does not undermine the importance of the social stresses. Among people with chronic pain that is resistant to physical therapies, interventions aimed at relieving social stresses, such as counselling or problem solving, may be beneficial for both back pain and depression (Mynors-Wallis et al., 2000; van den 
Hout et al., 2003). Alternatively, techniques that help individuals cope better with stresses, such as cognitive behavioural therapy, may benefit subsequent quality of life and reduce healthcare utilisation. Proof of the benefits of intervening with social stresses must be established through intervention studies, however.

Our findings confirm that anxiety, depression and fear-avoidance beliefs have important influences on physical aspects of HRQoL and healthcare utilisation in chronic low back pain sufferers. We agree with others who have recommended that clinicians treating disabled back pain patients should evaluate mental health (Wittink et al., 2003). Interventions directed at improving anxiety and depression are likely to benefit patients directly by reducing illness burden and have potential to substantially improve physical HRQoL and reduce health service utilisation. Treatment of depression may involve physical rehabilitation, non-specific exercise (Hurwitz et al., 2002; Smeets et al., 2006) or it may include the use of antidepressants, though the effect of these drugs in depressed back pain patients is not clear (Dickens et al., 2000; Jackson et al., 2000; Staiger et al., 2003). Optimum treatment strategies are likely to involve screening subjects for social and psychological problems alongside physical assessments. This will enable delivery of treatments based on individualised assessments of need, possibly using a stepped-care model, as has been used in diabetes (Katon et al., 2004). Using such a model, individuals with the most severe disability with marked treatment resistance may require elements from all of these strategies, possibly with case manager involvement to ensure delivery of treatment.

Further intervention trials are now required to identify how best to treat psychological problems, social problems and physical problems together in chronic pain patients. Assessments of combined treatments, such as antidepressants and psychological treatments, in addition to standard treatments for the physical problems, such as physiotherapy, are required. Furthermore studies are required to determine whether outcomes, such as physical health-related quality of life and healthcare utilisation, improve when specific treatment is offered for social stresses, depression and maladaptive beliefs about back pain in addition to usual rehabilitation techniques (Sullivan et al., 2006a).

\section{References}

Al Obaidi SM, Nelson RM, Al Awadhi S, Al Shuwaie N. The role of anticipation and fear of pain in the persistence of avoidance behavior in patients with chronic low back pain. Spine 2000;25:1126-31.

Asmundson GJ, Norton PJ, Norton GR. Beyond pain: the role of fear and avoidance in chronicity. Clin Psychol Rev 1999;19:97-119.
Beecham JK, Knapp MRJ. Costing psychiatric interventions. In: Thornicroft G, Brewin C, Wing JK, editors. Measuring mental health needs. London: Gaskell; 1992.

Boersma K, Linton SJ. How does persistent pain develop? An analysis of the relationship between psychological variables, pain and function across stages of chronicity. Behav Res Ther 2005a;43:1495-507.

Boersma K, Linton SJ. Screening to identify patients at risk: profiles of psychological risk factors for early intervention. Clin J Pain 2005b;21:38-43.

Boersma K, Linton SJ. Psychological processes underlying the development of a chronic pain problem: a prospective study of the relationship between profiles of psychological variables in the fear-avoidance model and disability. Clin J Pain 2006;22:160-6.

Brown G, Harris T. Social origins of depression: A study of psychiatric disorder in women. London: Tavistock; 1978.

Carragee EJ, Alamin TF, Miller JL, Carragee JM. Discographic, MRI and psychosocial determinants of low back pain disability and remission: a prospective study in subjects with benign persistent back pain. Spine J 2005;5:24-35.

Dickens C, Jayson M, Sutton C, Creed F, Dickens C, Jayson M, Sutton C, Creed F. The relationship between pain and depression in a trial using paroxetine in sufferers of chronic low back pain. Psychosomatics 2000;41:490-9.

Dionne CE, Von Korff M, Koepsell TD, Deyo RA, Barlow WE, Checkoway H. Formal education and back pain: a review. J Epidemiol Community Health 2001;55:455-68.

Gatchel RJ, Mayer T, Dersh J, Robinson R, Polatin P. The association of the SF-36 health status survey with 1-year socioeconomic outcomes in a chronically disabled spinal disorder population. Spine 1999;24:2162-70.

Goldthorpe JH, Hope K. The social grading of occupations. A new approach and scale. London: Oxford University Press; 1974.

Hartvigsen J, Lings S, Leboeuf-Yde C, Bakketeig L. Psychosocial factors at work in relation to low back pain and consequences of low back pain; a systematic, critical review of prospective cohort studies. Occup Environ Med 2004;61:e2.

Hurwitz EL, Morgenstern H, Harber P, Kominski GF, Belin TR, Yu F, Adams AH. Second prize: the effectiveness of physical modalities among patients with low back pain randomized to chiropractic care: findings from the UCLA low back pain study. J Manipulative Physiol Ther 2002;25:10-20.

Jackson JL, O'Malley PG, Tomkins G, Balden E, Santoro J, Kroenke $\mathrm{K}$. Treatment of functional gastrointestinal disorders with antidepressant medications: a meta-analysis. Am J Med 2000;108:65-72.

Katon WJ, Von Korff M, Lin EH, Simon G, Ludman E, Russo J, Ciechanowski P, Walker E, Bush T. The pathways study: a randomized trial of collaborative care in patients with diabetes and depression. Arch Gen Psychiatry 2004;61:1042-9.

Koleck M, Mazaux JM, Rascle N, Bruchon-Schweitzer M. Psychosocial factors and coping strategies as predictors of chronic evolution and quality of life in patients with low back pain: a prospective study. Eur J Pain 2006;10:1-11.

Linton SJ. A review of psychological risk factors in back and neck pain. Spine 2000;25:1148-56.

Little P, Somerville J, Williamson I, Warner G, Moore M, Wiles R, George S, Smith A, Peveler R. Psychosocial, lifestyle, and health status variables in predicting high attendance among adults. Br $\mathbf{~}$ Gen Pract 2001;51:987-94.

Mynors-Wallis LM, Gath DH, Day A, Baker F, Mynors-Wallis LM, Gath DH, Day A, Baker F. Randomised controlled trial of problem solving treatment, antidepressant medication, and combined treatment for major depression in primary care. Br Med $\mathbf{J}$ 2000;320:26-30.

Pfingsten M, Kroner-Herwig B, Leibing E, Kronshage U, Hildebrand J. Validation of the German version of the fear-avoidance belief questionnaire (FABQ). Eur J Pain 2000;4:259-66. 
Pincus T, Burton AK, Vogel S, Field AP, Pincus T, Burton AK, Vogel S, Field AP. A systematic review of psychological factors as predictors of chronicity/disability in prospective cohorts of low back pain. Spine 2002;27:E109-20.

Rose D, Pevalin DJ. The national statistics socio-economic classification: Unifying official and sociological approaches to the conceptualisation and measurement of social class. ISER Working papers. Paper 2001-4. Colchester: University of Essex.

Smeets RJ, Vlaeyen JW, Hidding A, Kester AD, van den Heijden GJ, van Geel AC, Knottnerus JA. Active rehabilitation for low back pain: cognitive-behavioral, physicl aor both? First direct posttreatment results from a rondomised controlled trial. BMC Musculoskelet Disord 2006:7.

Smith BH, Elliott AM, Hannaford PC, Chambers WA, Smith WC. Factors related to the onset and persistence of chronic back pain in the community: results from a general population follow-up study. Spine 2004;29:1032-40.

Staiger TO, Gaster B, Sullivan MD, Deyo RA, Staiger TO, Gaster B, Sullivan MD, Deyo RA. Systematic review of antidepressants in the treatment of chronic low back pain. Spine 2003;28:2540-5.

Sullivan MJ, Adams H, Thibault P, Corbiere M, Stanish WD. Initial depression severity and the trajectory of recovery following cognitive-behavioural intervention for work disability. J Occup Rehabil 2006a;16:63-74.

Sullivan MJ, Adams H, Rhodenizer T, Stanish WD. A psychosocial risk factor-targeted intervention for the prevention of chronic pain and disability following whiplash injury. Phys Ther 2006b;86:8-18.

Sullivan MJ, Feuerstein M, Gatchel R, Linton SJ, Pransky G. Integrating psychosocial and behavioral interventions to achieve optimal rehabilitation outcomes. J Occup Rehabil 2005a; $15: 475-89$.

Sullivan MJ, Stanish WD, Sullivan MJL, Stanish WD. Psychologically based occupational rehabilitation: the pain-disability prevention program. Clin J Pain 2003;19:97-104.

Sullivan MJ, Ward LC, Tripp D, French DJ, Adams H, Stanish WD. Secondary prevention of work disability: community-based psychosocial intervention for musculoskeletal disorders. J Occup Rehabil 2005b;15:377-92.

Swinkels-Meewisse IE, Roelofs J, Verbeek ALM, Oostendorp RA, Vlaeyen JWS. Fear-avoidance beliefs, disability, and participation in workers and nonworkers with acute low back pain. Clin J Pain 2006;22:45-54.

van den Hout JH, Vlaeyen JW, Heuts PH, Zijlema JH, Wijnen JA, van den Hout JHC, Vlaeyen JWS, Heuts PHTG, Zijlema JHL, Wijnen JAG. Secondary prevention of work-related disability in nonspecific low back pain: does problem-solving therapy help? A randomized clinical trial. Clin J Pain 2003;19:87-96.

Vlaeyen JW, Linton SJ. Fear-avoidance and its consequences in chronic musculoskeletal pain: a state of the art. Pain 2000;85:317-32.

Waddell G, Newton M, Henderson I, Somerville D, Main CJ, Waddell G, Newton M, Henderson I, Somerville D, Main CJ. A FearAvoidance Beliefs Questionnaire (FABQ) and the role of fearavoidance beliefs in chronic low back pain and disability. Pain 1993;52:157-68

Ware Jr JE, Kosinski M, Bayliss MS, McHorney CA, Rogers WH, Raczek A. Comparison of methods for the scoring and statistical analysis of SF-36 health profile and summary measures: summary of results from the Medical Outcomes Study. Med Care 1995;33:AS264-79.

Ware JE, Kosinski M, Keller S. SF-36 physical and mental health summary scales: A user's manual. Boston, Mass: The Health Institute, New England Medical Center; 1994.

Ware JE, Sherbourne CD. The MOS 36 item short-form health survey (SF-36): I. Conceptual framework and item selection. Med Care 1992;30:473-83.

Wittink H, Rogers W, Sukiennik A, Carr DB, Wittink H, Rogers W, Sukiennik A, Carr DB. Physical functioning: self-report and performance measures are related but distinct. Spine 2003;28:2407-13.

Zigmond AS, Snaith RP. The hospital anxiety and depression scale. Acta Psychiatr Scand 1983;67:361-70. 